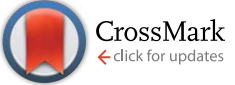

Cite this: RSC Adv., 2017, 7, 11085

Received 7th November 2016 Accepted 7th February 2017

DOI: $10.1039 / \mathrm{c} 6 \mathrm{ra} 26419 \mathrm{k}$

rsc.li/rsc-advances

\section{Preparation of $\gamma$-PGA hydrogels and swelling behaviors in salt solutions with different ionic valence numbers}

\author{
Zheng Li, ${ }^{\star a b}$ Guidong He, ${ }^{\text {ab }}$ Jiachuan Hua, ${ }^{\text {ab }}$ Maoqi Wu, ${ }^{\text {ab }}$ Wen Guo, ${ }^{\text {ab }}$ Jixian Gong, ${ }^{\text {ab }}$ \\ Jianfei Zhang*ab and Changsheng Qiao ${ }^{c}$
}

In this paper, a novel poly $\gamma$-glutamic acid ( $\gamma$-PGA) hydrogel was successfully synthesized by solution polymerization and ethylene glycol diglycidyl ether (EGDE) was used as crosslinker. The structure and morphology of the $\gamma$-PGA was investigated using scanning electron microscopy (SEM) and Fourier transform infrared spectroscopy (FTIR) techniques. The influence of ionic $\left(\mathrm{Na}^{+}, \mathrm{Ca}^{2+}\right.$ and $\mathrm{Fe}^{3+}$ ) concentrations, temperature and $\mathrm{pH}$ on the swelling degree of $\gamma$-PGA hydrogels was studied. The results revealed that the swelling capacity is enhanced with increasing $\mathrm{pH}$, but decreased with increasing ionic concentration. The swelling kinetics study indicated that $\gamma$-PGA hydrogels were ion-sensitive and presented more limited swelling kinetics in metal ion solutions with higher ionic valence numbers. The results showed that the pseudo-second-order adsorption kinetics were predominant. Maximum swelling degrees were obtained for $\gamma$-PGA hydrogels with $21.03 \mathrm{~g} \mathrm{~g}^{-1}$ in $0.154 \mathrm{~mol} \mathrm{~L}^{-1} \mathrm{NaCl}$ solution, $8.5 \mathrm{~g} \mathrm{~g}^{-1}$ in $0.154 \mathrm{~mol} \mathrm{~L}^{-1} \mathrm{CaCl}_{2}$ solution and $12.8 \mathrm{~g} \mathrm{~g}^{-1}$ in $0.154 \mathrm{~mol} \mathrm{~L}^{-1} \mathrm{FeCl}_{3}$ solution. Considering the simple preparation process, the ionic- and $\mathrm{pH}$-sensitive properties, this $\gamma$-PGA hydrogel might have high potential to be used in medical and other fields.

\section{Introduction}

Over the past few decades, hydrogels have been widely used as functional materials in many applications and fields, for example, tissue implants, ${ }^{1-3}$ drug delivery ${ }^{\mathbf{4}-6}$ and superabsorbents. ${ }^{7-9}$ The composition of hydrogels can be natural polymers or synthetic polymers. ${ }^{\mathbf{1 0}}$ New hydrogels with biocompatibility and stimuli-response capacity, developed from naturally occurring polymers, have been broadly investigated and applied in medical products in recent years. ${ }^{11-13}$ These hydrogels are promising matrix materials for biomedical and tissue engineering due to their biocompatibility, tunable biomimetic properties and capability of absorbing liquid. ${ }^{\mathbf{1 4}}$ As a result, hydrogels prepared from natural polymers were more developed in medical and tissue engineering such as wound dressings ${ }^{15}$ and absorbents, ${ }^{16}$ than in other fields. ${ }^{17,18}$

As newly developed absorbent materials, hydrogels can be practically cast into any size, shape or form. ${ }^{\mathbf{1 9}}$ Moreover, hydrogels can absorb liquid to reach a thousand-fold of their

${ }^{a}$ Key Laboratory of Advanced Textile Composites (Tianjin Polytechnic University), Ministry of Education, Tianjin 300387, China. E-mail: lizheng_nx@163.com; zhangjianfei1960@126.com; Tel: +8615822044516

${ }^{b}$ School of Textiles, Tianjin Polytechnic University, Tianjin 300387, China

'Key Laboratory of Industrial Microbiology, Ministry of Education, Tianjin University of Science and Technology, Tianjin 300457, China dry weight due to the hydrophilic groups in their polymeric networks. ${ }^{20}$

Poly $(\gamma$-glutamic acid), $\gamma$-PGA, is an unusual anionic poly amino acid linked by the peptide bond between the $\alpha$-amino group and the $\gamma$-carboxyl group ${ }^{21}$ (Scheme 1). Considerable attention has been focused on $\gamma$-PGA due to its water-solubility, biodegradability, edibility and non-toxicity towards human. ${ }^{22}$ As a result, $\gamma$-PGA and its derivatives have been broadly used in many industrial fields such as food industry, ${ }^{23,24}$ medicine, ${ }^{25,26}$ cosmetic $^{27,28}$ and agriculture. ${ }^{29}$ In addition, $\gamma$-PGA offers a wide range of applications in water and wastewater treatment, including highly water absorbable hydrogels, ${ }^{30,31}$ catalytic fibers, ${ }^{32}$ metal chelates ${ }^{33-35}$ and bioflocculants. ${ }^{36-38}$

During the past decades, our society has suffered a lot from the rapid growth of industrial ion wastewater. In order to study the applicability of hydrogels in wastewater treatment, we further investigated the ion absorption properties of hydrogels prepared from $\gamma$-PGA, poly( $N$-hydroxyethylacrylamide), ${ }^{\mathbf{1 6}}$ poly acrylic acid, ${ }^{39}$ poly aspartic acid and poly vinyl alcohol. It is commonly acknowledged that the swelling kinetic behavior of hydrogels in ion solutions is the major factor to determine their practicability. Therefore, it is important to further study this factor in more detail. Since the adsorption study of ion has been widely investigated, the main goal of this study has been focused on the effects of ionic valence number on the swelling kinetics of $\gamma$-PGA hydrogels. However, since hydrogels have been broadly applied in biomedical, it is of great necessary to 


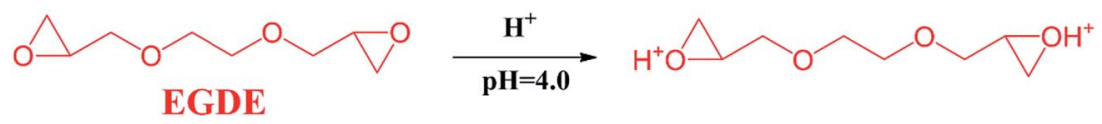

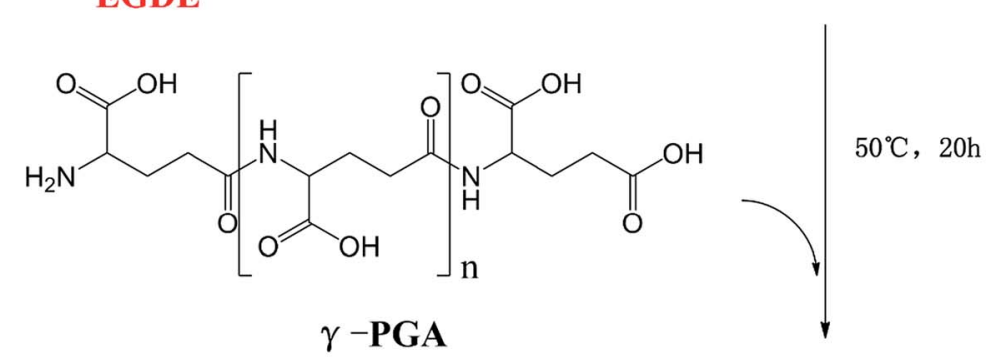

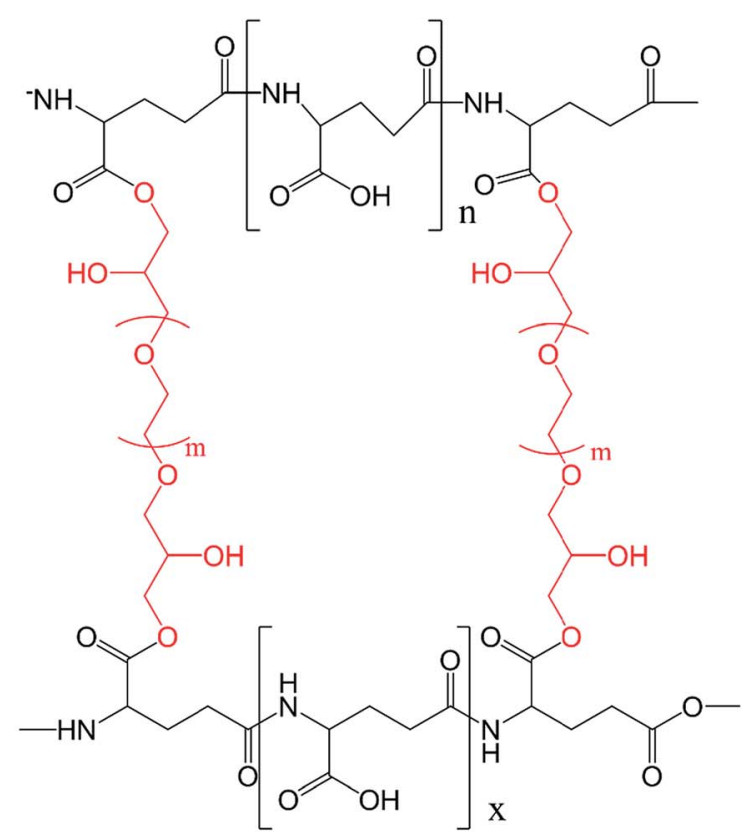

\section{$\gamma$-PGA Hydrogel}

Scheme 1 Synthetic of synthesis.

study how hydrogels, especially those that have been reported with ion-sensitive properties, swell in commonly used biological liquids that are rich in different ions, such as sweat $\left(\mathrm{Na}^{+}, \mathrm{K}^{+}\right)$, blood $\left(\mathrm{Ca}^{2+}, \mathrm{Fe}^{2+}, \mathrm{Fe}^{3+}\right)$ and urine $\left(\mathrm{Na}^{+}, \mathrm{K}^{+}\right)$. In previous studies, $\gamma$-PGA hydrogels were prepared by UV, ${ }^{40} \gamma$-irradiation, ${ }^{31}$ chemical reagents. ${ }^{41-43}$ However, $\gamma$-PGA hydrogels prepared by $\gamma$-PGA and ethylene glycol diglycidyl ether (EGDE) are a representative model to research the swelling behavior of poly amino acid hydrogels. The preparation of these hydrogels only needs a simple aqueous mixture process which is convenient to control. ${ }^{44}$ Besides, $\mathrm{NaCl}, \mathrm{CaCl}_{2}$, and $\mathrm{FeCl}_{3}$ were chosen to study how $\gamma$-PGA hydrogels swelled in ionic solutions with different valence numbers.

To achieve this, we prepared $\gamma$-PGA hydrogels by EGDE via a simple mixture process in the aqueous solution in this paper. The chemical characteristics was analyzed by FTIR and SEM. Moreover, we studied the effects of ionic concentration, temperature and $\mathrm{pH}$ on the swelling kinetics. The pseudo-firstorder and pseudo-second-order equations were utilized to verify the mechanism and kinetics of the swelling process.

\section{Materials and methods}

\subsection{Materials}

$\gamma$-Polyglutamic acid ( $\gamma$-PGA, average molecular weight, $730 \mathrm{kDa})$ was purchased from Shineking Biotechnology (Nanjing, China). Ethylene glycol diglycidyl ether (EGDE) was purchased from Tongshi Chemical Ltd. (Yantai, China). $\mathrm{NaCl}, \mathrm{CaCl}_{2}$, and $\mathrm{FeCl}_{3} \cdot 6 \mathrm{H}_{2} \mathrm{O}$ were purchased from Sinopharm group Co. Ltd (Shanghai, China).

\subsection{Preparation of $\gamma$-PGA hydrogel}

$\gamma$-PGA hydrogels were synthesized by a simple mixture process in the aqueous solution (Scheme 1). $\gamma$-PGA was dissolved in deionized water to a $12 \%$ wt aqueous solution, and then ethylene glycol diglycidyl ether (EGDE) was added as the crosslinking agent. The weight of EGDE was equal to $40 \%$ of the weight of $\gamma$-PGA. The $\mathrm{pH}$ of the solutions was adjusted to 4.0, and the mixture was maintained at $50{ }^{\circ} \mathrm{C}$ for $20 \mathrm{~h}$. The formed hydrogel was cut into cubes with an approximately $2 \mathrm{~mm}$ side 
length and immersed in an excess of deionized water for 1 week with daily water exchanges to remove the unreacted monomer.

\subsection{Chemical characterization}

The structure of $\gamma$-PGA hydrogel samples was analysed by Fourier transform infrared (FTIR) spectra (Thermo Fisher Technology, America). The scan mode was the transmittance mode with a $4 \mathrm{~cm}^{-1}$ scan resolution. $\gamma$-PGA hydrogel samples were freeze dried and smashed to powder.

SEM (TM-3030, Hitachi, Japan) was used to observe the surface and cross-section morphologies of the hydrogels. First, freeze dried $\gamma$-PGA hydrogel samples were immobilized by Hardy fiber microtome. Then the surface samples and crosssection samples were cut into $1 \mathrm{~mm}$ slices. Finally, all samples were coated with gold for $10 \mathrm{~s}$ prior to SEM observation (accelerating voltage $=5000 \mathrm{~V}$ ).

All freeze dried $\gamma$-PGA hydrogel samples were swelled to equilibrium in different swelling media and then were prefrozen at $-10{ }^{\circ} \mathrm{C}$ for $3 \mathrm{~h}$ in an ultra-low temperature freezer (DW-HL388, Meiling Cryogenic Technology, China). Finally, samples were freeze dried in a freeze-dryer (FD-1CL, DTY Technology, China).

\subsection{The swelling capacity in different conditions}

2.4.1. The effect of ion concentration. As shown in Table 1, the swelling capacities of $\gamma$-PGA hydrogels were determined in $\mathrm{NaCl}, \mathrm{CaCl}_{2}$ and $\mathrm{FeCl}_{3}$ solutions with different concentrations according to the above method described in a previous study, respectively. ${ }^{16}$

2.4.2. The effect of temperature. The swelling capacities of $\gamma$-PGA hydrogels were determined in $0.154 \mathrm{~mol} \mathrm{~L}^{-1} \mathrm{NaCl}, \mathrm{CaCl}_{2}$ and $\mathrm{FeCl}_{3}$ solutions according to the above method described in a previous study, respectively. ${ }^{16}$ The temperatures of the swelling environment were set to be $15,30,45$ and $60{ }^{\circ} \mathrm{C}$ in a cultivation tank, respectively.

2.4.3. The effect of $\mathbf{p H}$. The swelling capacities of $\gamma$-PGA hydrogels were determined in $0.154 \mathrm{~mol} \mathrm{~L}^{-1} \mathrm{NaCl}$ and $\mathrm{CaCl}_{2}$ solutions according to the above method described in a previous study, respectively. ${ }^{16}$ The pHs of the swelling environment were set to be $1,2,3,4,5,6$ and 7 , respectively. The desired acidic pHs were adjusted by $\mathrm{HCl}$ solution. The pHs were precisely determined by a $\mathrm{pH}$ meter.

\subsection{Swelling kinetics study}

$\gamma$-PGA hydrogel cubes $(5 \times 5 \times 5 \mathrm{~mm})$ were previously dried at $50{ }^{\circ} \mathrm{C}$. The weights of the wet hydrogels $\left(W_{\mathrm{o}}\right)$ were measured at predetermined time while equilibrium in different swelling media at room temperature. The hydrogels were then thoroughly dried and the weights of the dry hydrogels $\left(W_{\mathrm{d}}\right)$ were measured. ${ }^{45,46}$ The swelling degree $(Q)$ was calculated from the following expression (1):

$$
Q=\left(W_{\mathrm{o}}-W_{\mathrm{d}}\right) / W_{\mathrm{d}}
$$

The rate of swelling in DI water for PGA hydrogels can be readily obtained from the equation for the pseudo-first-order and pseudo-second-order models derived on the basis of swelling capacity on solid phase expressed (2) and (3) as follows, respectively: ${ }^{16}$

$$
\begin{gathered}
\lg \left(Q_{\mathrm{e}}-Q_{t}\right)=\lg Q_{\mathrm{e}}-\frac{K_{1} t}{2.303} \\
\frac{t}{Q_{t}}=\frac{1}{K_{2} Q_{\mathrm{e}}{ }^{2}}+\frac{t}{Q_{\mathrm{e}}}
\end{gathered}
$$

where $Q_{t}\left(\mathrm{~g} \mathrm{~g}^{-1}\right)$ and $Q_{\mathrm{e}}\left(\mathrm{g} \mathrm{g}^{-1}\right)$ are the amount of swelling in equilibrium and at time $t$, respectively; $K_{1}\left(\min ^{-1}\right)$ and $K_{2}$ $\left(\mathrm{min}^{-1}\right)$ are the rate constant.

\section{Results and discussion}

\subsection{Preparation and characterization of $\gamma$-PGA hydrogels}

$\gamma$-PGA hydrogels were prepared by a simple mixture process in the aqueous solution (Scheme 1). At the beginning, under acidic condition, $\mathrm{H}^{+}$combined with the epoxy group from EGDE and formed the ionized hydrogen group. Then, nucleophilic addition happened between - $\mathrm{COOH}$ from $\gamma$-PGA and the ionized epoxy group. Finally, $\mathrm{H}^{+}$was separated and crosslinking bond was formed. The whole reaction mechanism belonged to $\mathrm{S}_{\mathrm{N}} 2$ type. ${ }^{47}$

As shown in Fig. 1, FTIR spectroscopy was carried out to further confirm the crosslinking reaction. The broad peak at around $3436 \mathrm{~cm}^{-1}$ is attributed to the overlap of $\mathrm{N}-\mathrm{H}$ and $\mathrm{O}-\mathrm{H}$ stretching vibrations. The peak located at $1080.1 \mathrm{~cm}^{-1}$ arises from the stretching vibrations of $\mathrm{C}-\mathrm{O}-\mathrm{C}$ bond due to the addition of EGDE. ${ }^{48}$ It shows that there is ether bond in the $\gamma$-PGA hydrogel. ${ }^{49}$ In addition, it is worth noting that the peak at 1639.4 $\mathrm{cm}^{-1}$ strengthened while the peak at $1702.4 \mathrm{~cm}^{-1}$ weakened in $\gamma$-PGA hydrogels. These peaks belong to the $\mathrm{C}=\mathrm{O}$ stretching of ester and the $\mathrm{C}=\mathrm{O}$ stretching of the carbonyl (the peak I of carbonyl), ${ }^{50}$ respectively. This indicates that the crosslinking reaction occurred between the carbonyl of $\gamma$-PGA and the epoxide groups of EGDE and then ester bond formed. All of these changes illustrate that there is chemical reaction between EGDE and $\gamma$-PGA, and the reaction leads to the formation of new ester bond as crosslinking linkage.

\begin{tabular}{|c|c|c|c|c|c|c|c|c|c|}
\hline & N1 & N2 & N3 & $\mathrm{C} 1$ & C2 & C3 & F1 & F2 & F3 \\
\hline Metal ion & $\mathrm{NaCl}$ & & & $\mathrm{CaCl}_{2}$ & & & $\mathrm{FeCl}_{3}$ & & \\
\hline Molar concentrations $\left(\mathrm{mol} \mathrm{L}^{-1}\right)$ & 0.154 & 0.769 & 1.539 & 0.154 & 0.769 & 1.539 & 0.015 & 0.077 & 0.154 \\
\hline
\end{tabular}

Table 1 Concentrations of $\mathrm{NaCl}, \mathrm{CaCl}_{2}$ and $\mathrm{FeCl}_{3}$ solutions (N1, N2 and N3 indicate the different concentrations of $\mathrm{Na}^{+}$. C1, C2 and C3 indicate the different concentrations of $\mathrm{Ca}^{2+}$. F1, F2 and F3 indicate the different concentrations of $\mathrm{Fe}^{3+}$ ) 


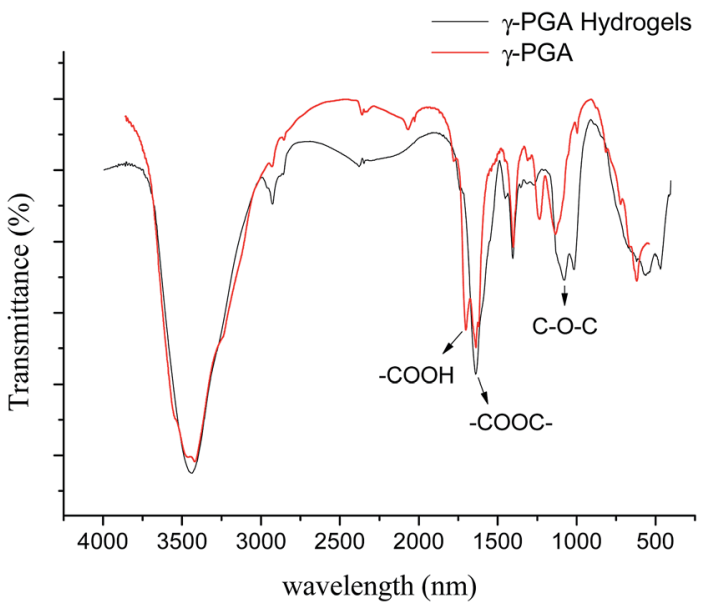

Fig. 1 FTIR spectra of $\gamma$-PGA and $\gamma$-PGA hydrogel.

To observe the macroscopic form and the microstructure of $\gamma$-PGA hydrogels, the morphology of swelling equilibrium hydrogels was listed in Table 2. As was shown in Table 2 (a), (b) and (c), after swelling equilibrium, the form of $\gamma$-PGA hydrogels displayed a similar color as swelled ionic solutions and kept a regular cubic shape. This indicated that swelled $\gamma$-PGA hydrogels also adsorbed metal ions into its structure, and this means that $\gamma$-PGA hydrogels have appropriate mechanical strength to be applied.

The surface and cross-section morphology of hydrogels was visualized by SEM. Table 2 presented a three dimensional network, and the porous structure of hydrogels was densely covered with irregularly shaped holes. As the ionic valence number increased, the networks became smaller. When swelled in $\mathrm{FeCl}_{3}$ solution, the porous structure in hydrogels collapsed and showed narrowly shaped micropores. These trends suggested that increasing ionic valence number may restrict the swelling behavior of hydrogels. ${ }^{51}$ As shown in Table 2, $\gamma$-PGA hydrogels swelled in different ionic solutions did not have any significant change in the surface. The result showed that $\gamma$-PGA hydrogels swelled in DI water and ionic solutions both have a rough wrinkled surface without obvious holes. ${ }^{10}$

\subsection{The effects of ionic concentration, temperature and $\mathbf{p H}$}

3.2.1. The effect of temperature. Fig. 2 depicts the effect of temperature on the swelling capacity of $\gamma$-PGA hydrogels. In general, the swelling degree of $\gamma$-PGA hydrogels in NaCl solution was slightly raised with the temperature increasing from 15 to $60{ }^{\circ} \mathrm{C}$. But in $\mathrm{CaCl}_{2}$ and $\mathrm{FeCl}_{3}$ solutions, the swelling degree barely changed with the temperature rise. This indicated that the swelling process of $\gamma$-PGA hydrogels is slightly influenced by the

Table 2 The morphology of $\gamma$-PGA hydrogels after swelling equilibrium in 0.154 mol L ${ }^{-1} \mathrm{NaCl}_{1} \mathrm{CaCl}_{2}, \mathrm{FeCl}_{3}$ solutions

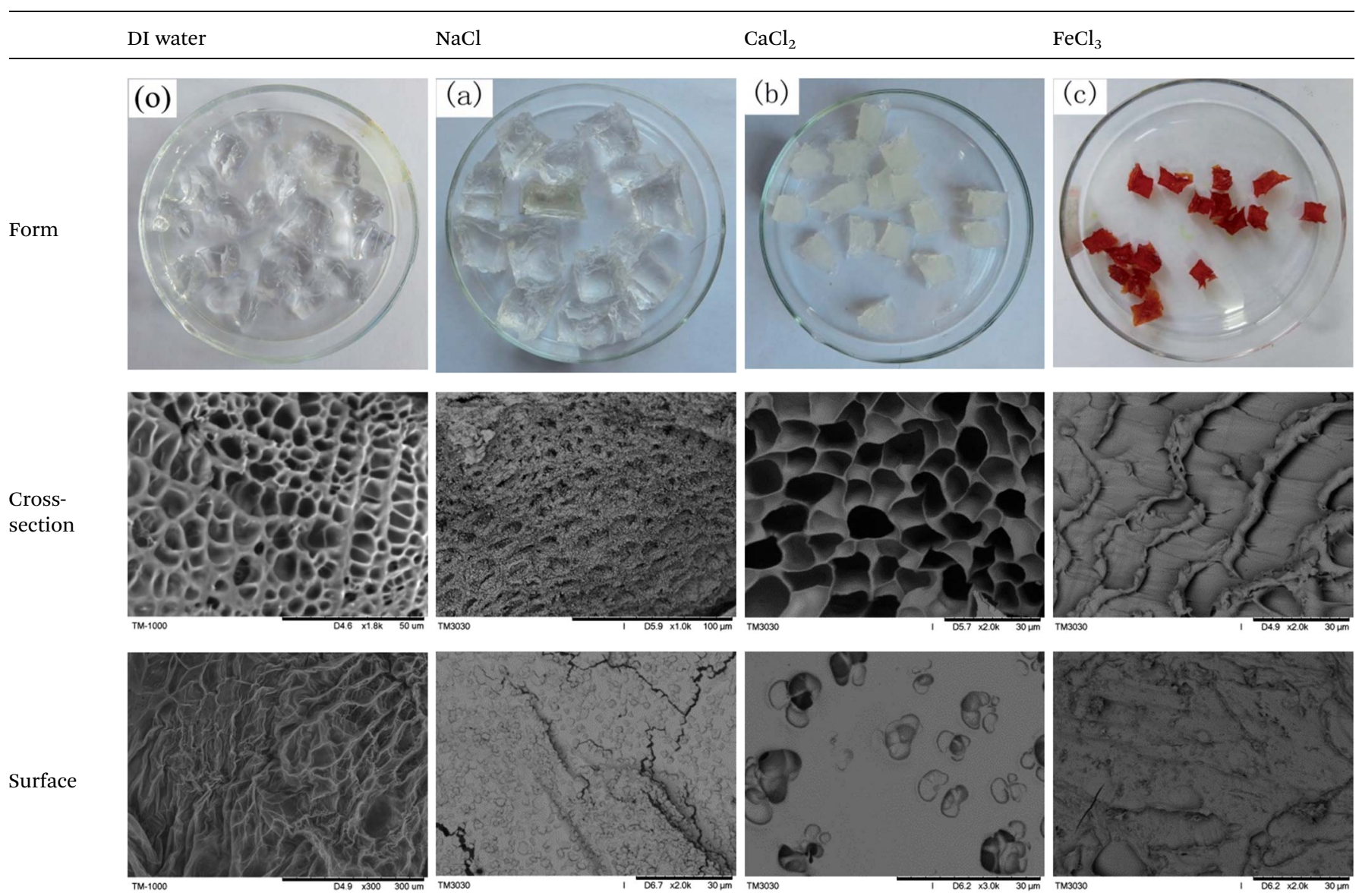




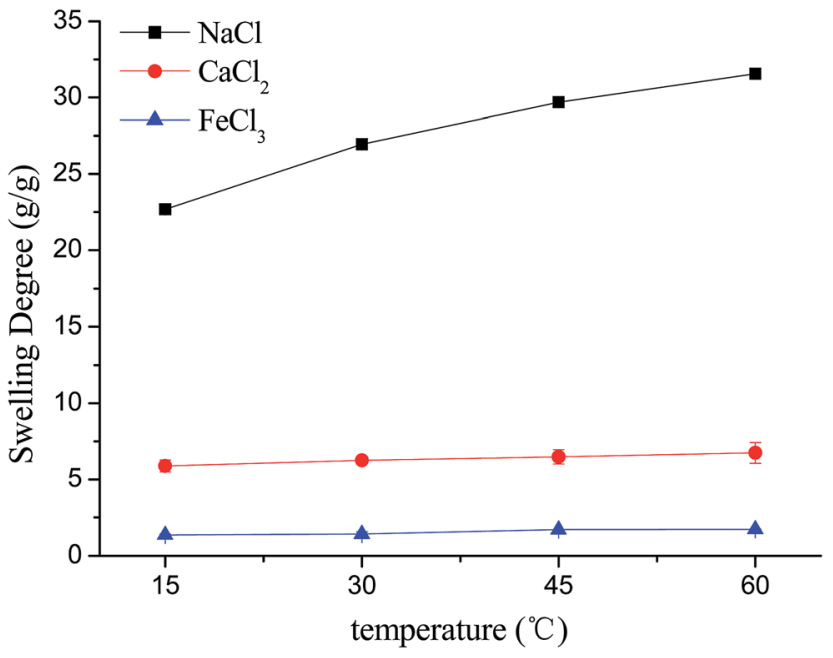

Fig. 2 The effect of temperature on the swelling behavior of $\gamma$-PGA hydrogels.

temperature in $\mathrm{NaCl}$ solution and is barely affected in $\mathrm{CaCl}_{2}$ and $\mathrm{FeCl}_{3}$ solutions. Compared to poly( $N$-hydroxyethylacrylamide) hydrogels, $\gamma$-PGA hydrogels presented the similar phenomenon that the effect of temperature was unapparent. ${ }^{\mathbf{1 6}}$

3.2.2. The effect of ionic concentration. The effect of solution concentration on the swelling capacity of $\gamma$-PGA hydrogels was shown in Fig. 3. Generally, the swelling capacity was decreased with the increase of ionic concentration according to the Flory's theory ${ }^{52}$ that the charge screening effect of increased additional cations causing a weakened electrostatic repulsion between $-\mathrm{COO}^{-}$, led to a depressed swelling on the polymer network.

It is worth noting that the swelling degree of hydrogels was significantly reduced with the ionic valence number advancing. As a result of deswelling of $\gamma$-PGA hydrogels, metal ions with a higher valence number also caused a weakened electrostatic repulsion between $-\mathrm{COO}^{-}$due to the chelation between $-\mathrm{COO}^{-}$ and metal ions. ${ }^{53}$

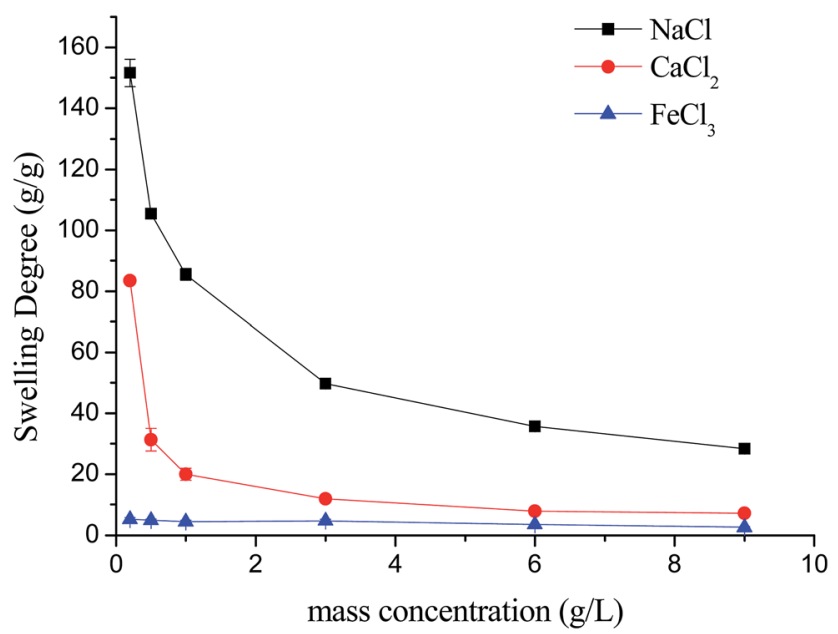

Fig. 3 The effect of solution concentration on the swelling behavior of $\gamma$-PGA hydrogels.
3.2.3. The effect of pH. Fig. 4 depicts the effect of $\mathrm{pH}$ on the swelling capacity of $\gamma$-PGA hydrogels. As $\mathrm{Fe}^{3+}$ will form precipitates when $\mathrm{pH}$ is higher (about 3), the effect of $\mathrm{pH}$ in $\mathrm{FeCl}_{3}$ solution was not studied. Generally, increasing $\mathrm{pH}$ enhanced the swelling capacity of the hydrogel. This phenomenon was attributed to the theory that the $-\mathrm{COO}^{-}$groups within the network of hydrogels were protonated at a lower $\mathrm{pH}^{.52,54}$ The metal ions had to compete with the proton for absorbency, and the protonated functional groups hindered the interaction between the hydrogel and metal cations. ${ }^{16}$

Scheme 2 described the swelling-deswelling network structure of $\gamma$-PGA hydrogels at various $\mathrm{pH}$ levels. In low $\mathrm{pH}$ range (12 ), there were more cations in the solution, $-\mathrm{COO}^{-}$groups were protonated and the repelling force between $-\mathrm{COO}^{-}$and $-\mathrm{COO}^{-}$ was weak. With the increasing of $\mathrm{pH}$, the amounts of $-\mathrm{COO}^{-}$ were also increased and this caused a stronger rejection force. As a result, the swelling degree was increased with the increasing of $\mathrm{pH}$.

\subsection{Swelling kinetics study}

3.3.1. The effect of ionic valence number. As shown in Fig. 5 and Scheme 3, the swelling kinetics of $\gamma$-PGA hydrogels in $\mathrm{NaCl}, \mathrm{CaCl}_{2}$ and $\mathrm{FeCl}_{3}$ solutions presented different trends. At the beginning, the swelling degree increased rapidly in $\mathrm{NaCl}$, $\mathrm{CaCl}_{2}$ and $\mathrm{FeCl}_{3}$ solutions. Then at around $200 \mathrm{~min}$, the elevation of swelling degrees slowed down in both $\mathrm{NaCl}$ and $\mathrm{CaCl}_{2}$ solutions, which surprisingly began to drop in $\mathrm{FeCl}_{3}$ solution. At the last stage, the swelling degrees kept on a steady level in both solutions. Finally, the experimental swelling degrees of $\gamma$-PGA hydrogels in $\mathrm{NaCl}, \mathrm{CaCl}_{2}$ and $\mathrm{FeCl}_{3}$ solutions were 20.44, 8.47, $1.48 \mathrm{~g} \mathrm{~g}^{-1}$, respectively.

Compared to poly(aspartic acid) hydrogels, the swelling kinetics of $\gamma$-PGA hydrogels were more likely to be influenced by ions. ${ }^{52}$ This phenomenon can be explained by the chemical structure of $\gamma$-PGA hydrogels which contained a vast amount of $-\mathrm{COOH}$ in the polymeric network. ${ }^{55}$ As a result, $\gamma$-PGA hydrogels were more ion-sensitive and presented more limited swelling

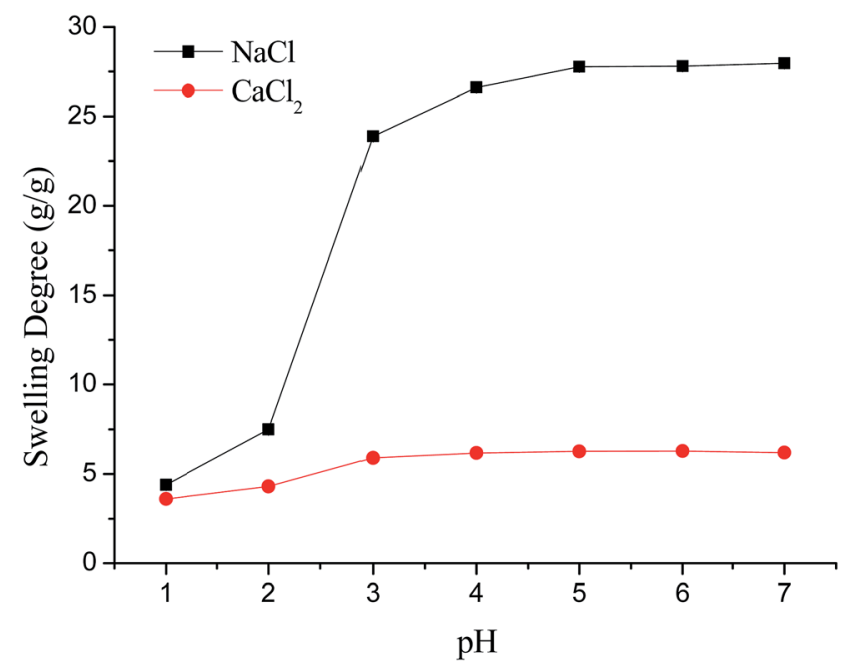

Fig. 4 The effect of $\mathrm{pH}$ on the swelling behavior of $\gamma$-PGA hydrogels. 


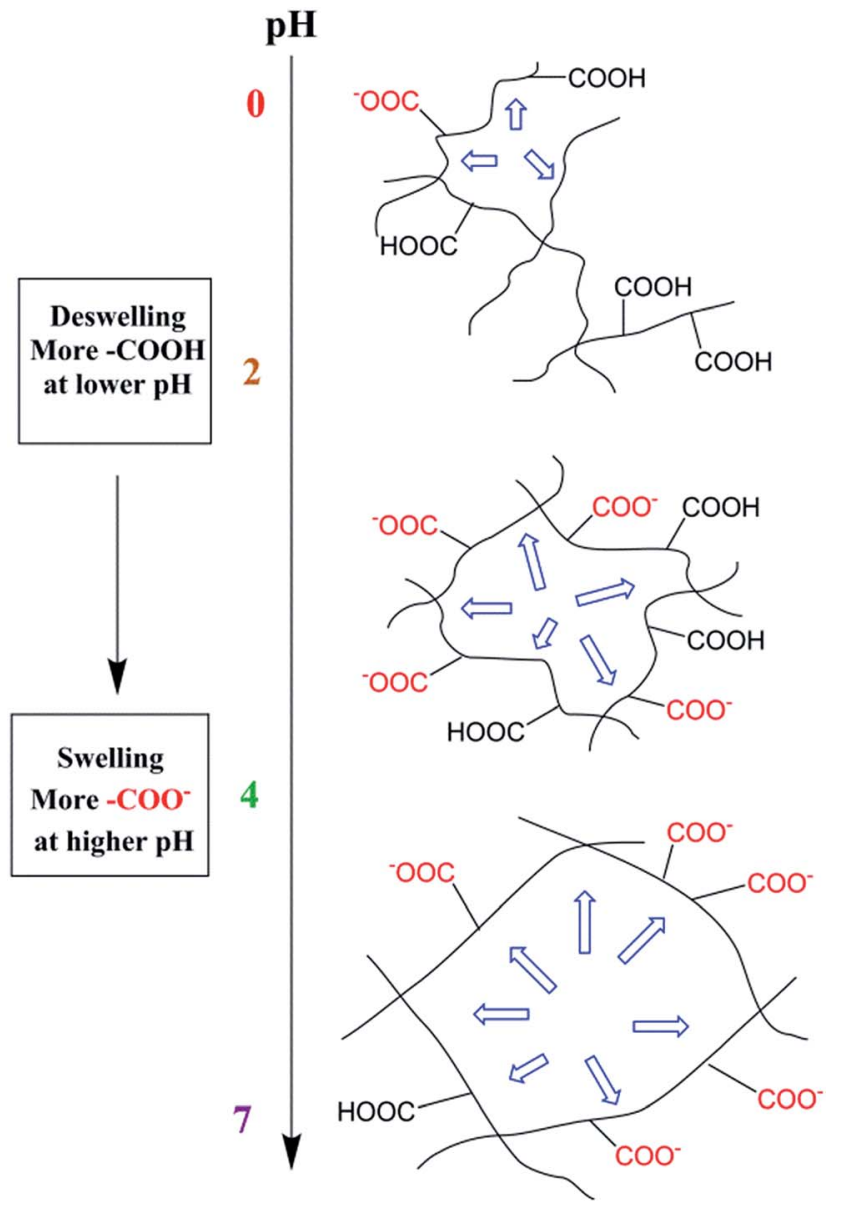

Scheme 2 A scheme of the swelling-deswelling network structure of $\gamma$-PGA hydrogels at various $\mathrm{pH}$ levels.

kinetics in metal ion solutions with higher ionic valence numbers.

3.3.2. The effect of $\mathrm{NaCl}$ concentration. To study the effect of $\mathrm{NaCl}$ concentration on the swelling kinetics of $\gamma$-PGA

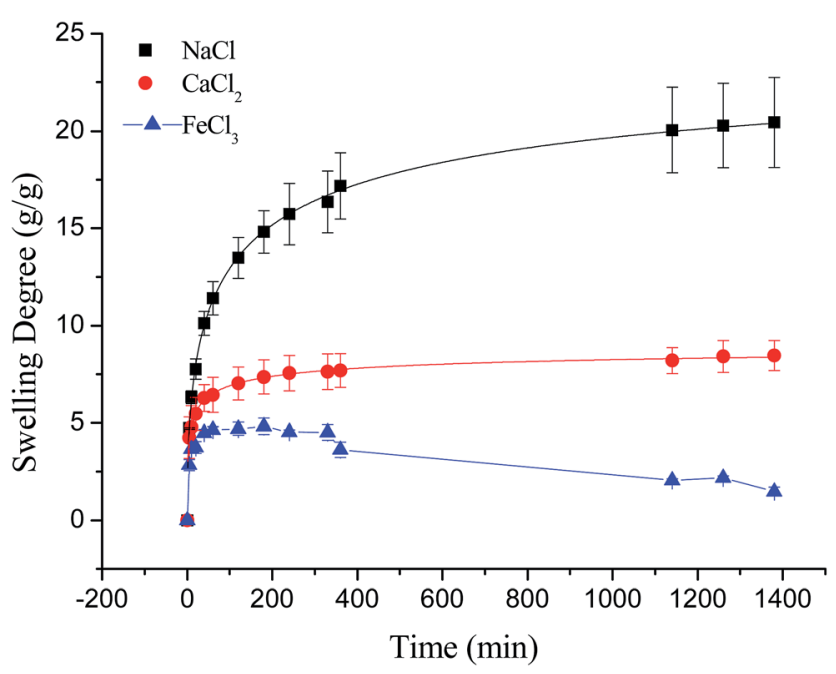

Fig. 5 The swelling kinetics of $\gamma$-PGA hydrogels in $\mathrm{NaCl}, \mathrm{CaCl}_{2}$ and $\mathrm{FeCl}_{3}$ solutions.

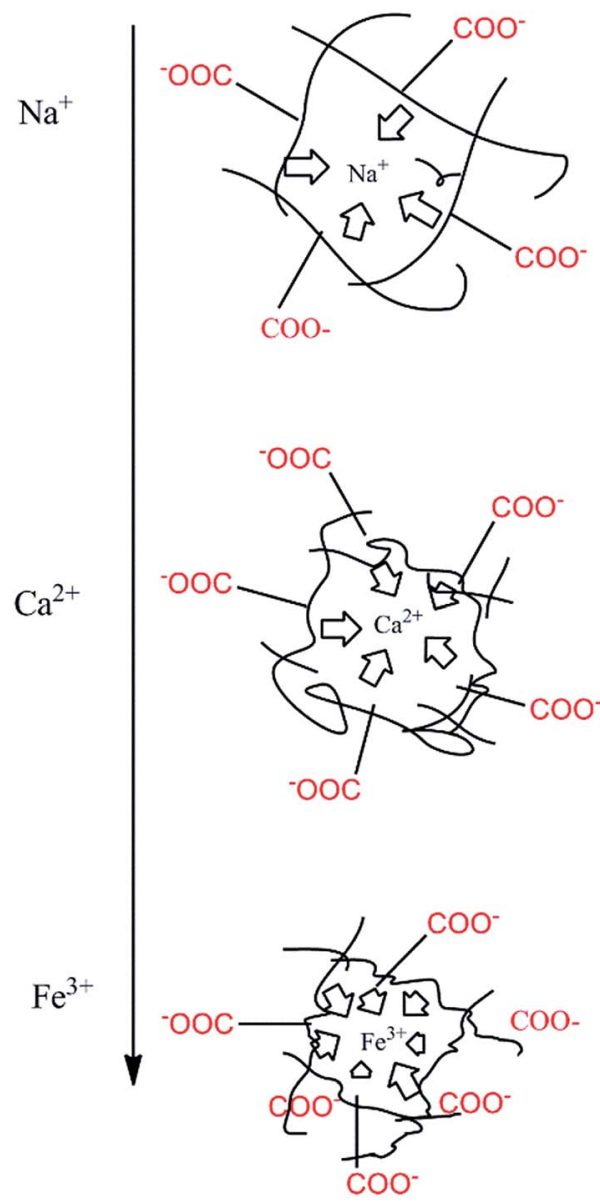

Scheme 3 A scheme of the ionic charge screening effect.

hydrogels, the swelling degrees at predetermined time were measured and the swelling kinetics of $\gamma$-PGA hydrogels was fitted by kinetic models. Among several established kinetic models, the pseudo-first-order and pseudo-second-order kinetic models were the most broadly applied models for investigating the swelling kinetics in ionic solutions such as $\mathrm{Pb}^{2+}$ and $\mathrm{Cu}^{2+}$ ionic solution. ${ }^{16}$

Fig. 6 depicted the plots for pseudo-first-order and pseudosecond-order model in N1, N2 and N3. Table 3 listed the kinetic parameters of pseudo-first-order and pseudo-secondorder models. In contrast to the pseudo-first-order, pseudosecond-order model displayed a relatively higher correlation coefficient $\left(R_{\mathrm{adj}}^{2}>0.99\right)$, and had a closer calculated equilibrium swelling degree $\left(Q_{e, c}\right)$ to the experimental equilibrium swelling degree $\left(Q_{\mathrm{e}, \mathrm{e}}\right)$. These indicated that the pseudo-secondorder model was more appropriate for fitting the experimental kinetics data, and also presented that the rate limiting step of swelling in $\mathrm{NaCl}$ was chemisorption or chelation involving valence forces through the sharing or exchange of electrons between the $\gamma$-PGA hydrogel and metal ions. ${ }^{16}$

As shown in Fig. 7, the swelling kinetics of $\gamma$-PGA hydrogels in both concentrations presented similar trends. The swelling degrees curves showed a sharper transition from the high initial rate to the slow rate towards the end of the swelling process, 


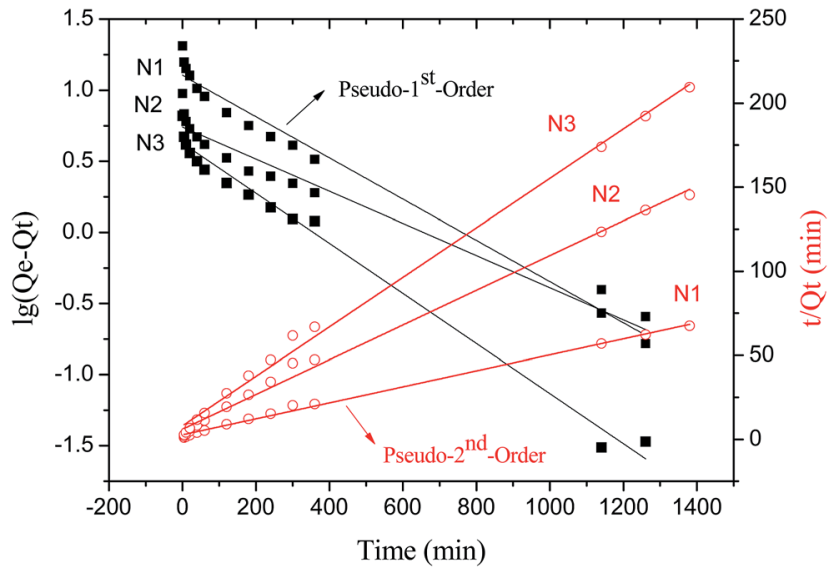

Fig. 6 The plots for pseudo-first and-second-order model in $\mathrm{NaCl}$ solution.

which was consistent with the previous study. ${ }^{43,56}$ Compared to $\gamma$-PGA/E-polylysine hydrogels, $\gamma$-PGA hydrogels presented a more limited swelling kinetics and a lower swelling degree in $\mathrm{NaCl}$ solution. This is due to the fact that $\gamma$-PGA/E-polylysine hydrogels contained both deprotonatable $-\mathrm{COOH}$ and protonatable $-\mathrm{NH}_{2}$. This structure can alleviate the charge screening effect of ions in network. ${ }^{43}$

3.3.3. The effect of $\mathbf{C a C l}_{2}$ concentration. Similar to the swelling kinetics in $\mathrm{NaCl}$ solution, the swelling kinetics of $\gamma$ PGA hydrogels in $\mathrm{CaCl}_{2}$ solution also presented typical pseudosecond-order kinetics curves. Fig. 8 showed the plots for pseudo-first-order and pseudo-second-order model in C1, C2 and C3. Table 4 listed the kinetic parameters of pseudo-firstorder and pseudo-second-order models. In contrast to the pseudo-first-order, pseudo-second-order model presented a relatively higher correlation coefficient $\left(R_{\mathrm{adj}}{ }^{2}>0.99\right)$, and had a closer calculated equilibrium swelling degree $\left(Q_{\mathrm{e}, \mathrm{c}}\right)$ to the experimental equilibrium swelling degree $\left(Q_{\mathrm{e}, \mathrm{e}}\right)$. These indicated that the pseudo-second-order model was more appropriate for fitting the experimental kinetics data, and also presented that the rate limiting step of swelling in $\mathrm{CaCl}_{2}$ solutions was also chemisorption or chelation involving valence forces through the sharing or exchange of electrons between the $\gamma$-PGA hydrogel and metal ions (Fig. 9).

3.3.4. The effect of $\mathbf{F e C l}_{3}$ concentration. As shown in Fig. 10, the swelling kinetics of $\gamma$-PGA hydrogels in $\mathrm{FeCl}_{3}$ solution presented different trends compared to those in $\mathrm{NaCl}$ and $\mathrm{CaCl}_{2}$ solutions. At the beginning, the swelling degrees were increased rapidly as was observed in $\mathrm{NaCl}$ and $\mathrm{CaCl}_{2}$ solutions.

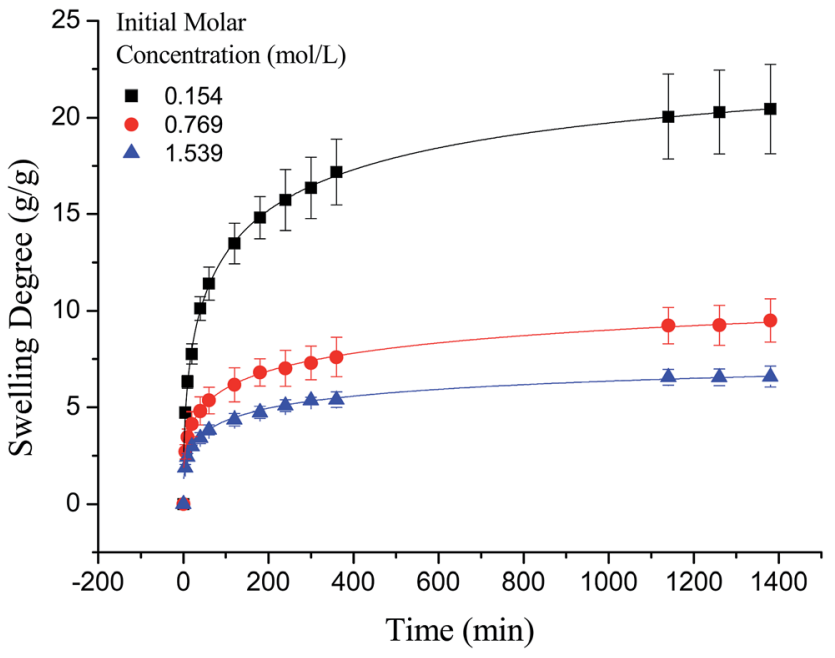

Fig. 7 The swelling kinetics of $\gamma$-PGA hydrogels in $\mathrm{NaCl}$ solution.

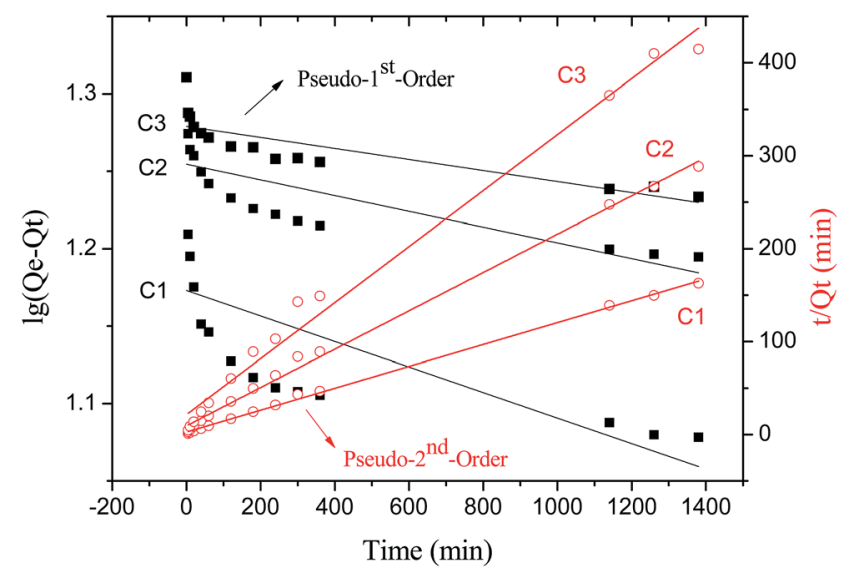

Fig. 8 The plots for pseudo-first and-second-order model in $\mathrm{CaCl}_{2}$ solution.

However, when $\gamma$-PGA hydrogels swelled at $330 \mathrm{~min}$, the swelling degrees were then decreased and dropped in merely about $5 \mathrm{~g} \mathrm{~g}^{-1}$. This may be due to the stronger charge screening effect of $\mathrm{Fe}^{3+}$ compared to $\mathrm{Na}^{+}$and $\mathrm{Ca}^{2+}$. When $\gamma$-PGA hydrogels adsorbed $\mathrm{Fe}^{3+}$ ions and reached the critical point, the strong attractive force between $-\mathrm{COO}^{-}$and $\mathrm{Fe}^{3+}$ equal to the total rejection force between $-\mathrm{COO}^{-}$and $-\mathrm{COO}-$ and other forces caused swelling at that moment. Then hydrogels adsorbed more ions, the strong attractive force between $-\mathrm{COO}^{-}$and $\mathrm{Fe}^{3+}$ became stronger and caused the collapse of the network in

Table 3 Rate constants and calculated swelling degrees of $\gamma$-PGA hydrogels in $\mathrm{NaCl}$ solution

\begin{tabular}{|c|c|c|c|c|c|c|c|}
\hline & $Q_{\mathrm{e}, \mathrm{e}}\left(\mathrm{g} \mathrm{g}^{-1}\right)$ & \multicolumn{3}{|c|}{ Pseudo-first-order } & \multicolumn{3}{|c|}{ Pseudo-second-order } \\
\hline N2 & 8.39 & 0.002602 & 5.51 & 0.9577 & 0.001775 & 9.68 & 0.9946 \\
\hline N3 & 6.05 & 0.004053 & 4.24 & 0.9842 & 0.002703 & 6.79 & 0.9959 \\
\hline
\end{tabular}


Table 4 Rate constants and calculated swelling degrees of $\gamma$-PGA hydrogels in $\mathrm{CaCl}_{2}$ solution

\begin{tabular}{|c|c|c|c|c|c|c|c|}
\hline & $Q_{\mathrm{e}, \mathrm{e}}\left(\mathrm{g} \mathrm{g}^{-1}\right)$ & \multicolumn{3}{|c|}{ Pseudo-first-order } & \multicolumn{3}{|c|}{ Pseudo-second-order } \\
\hline $\mathrm{C} 2$ & 4.79 & 0.000117 & 17.97 & 0.5533 & 0.004540 & 4.85 & 0.9967 \\
\hline C3 & 3.33 & 0.000082 & 19.01 & 0.6868 & 0.004230 & 3.32 & 0.9883 \\
\hline
\end{tabular}

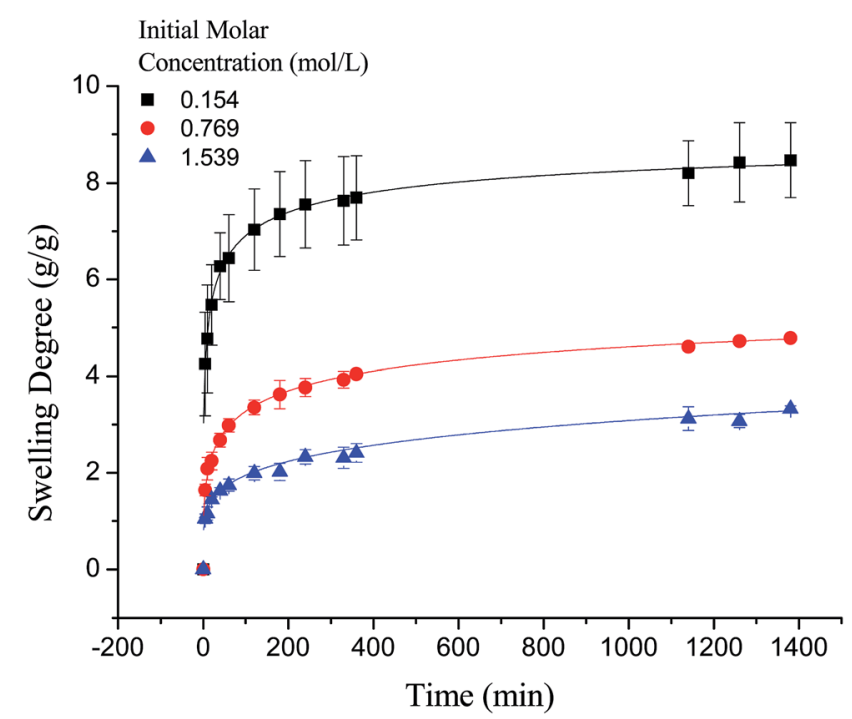

Fig. 9 The swelling kinetics of $\gamma$-PGA hydrogels in $\mathrm{CaCl}_{2}$ solution.

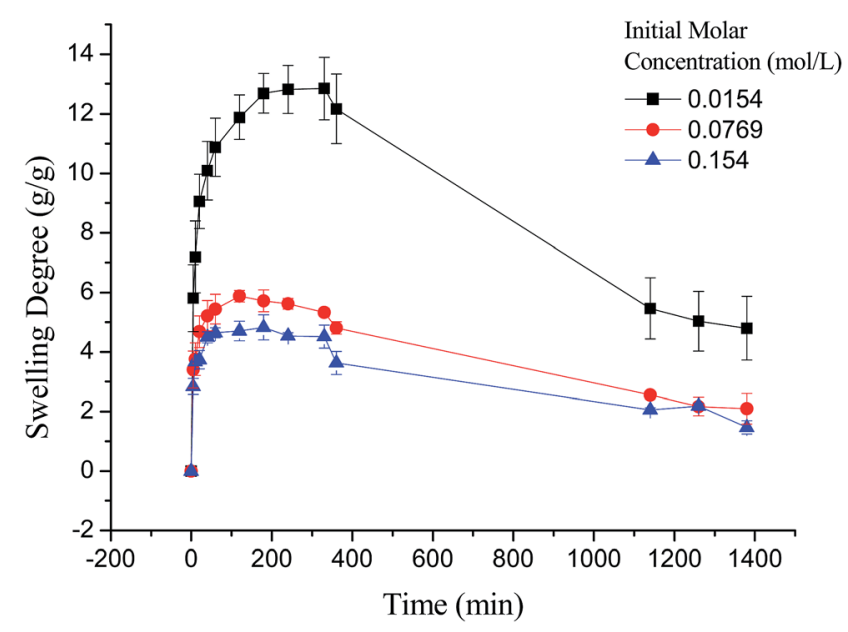

Fig. 10 The swelling kinetics of $\gamma$-PGA hydrogels in $\mathrm{FeCl}_{3}$ solution.

hydrogels. Finally, $\gamma$-PGA hydrogels reached equilibrium state as was shown in Table 2, and the swelling degrees in $0.0154 \mathrm{~mol}$ $\mathrm{L}^{-1}$ solution dropped from 12.8 to $4.8 \mathrm{~g} \mathrm{~g}^{-1}$.

\section{Conclusion}

In the study, $\gamma$-PGA hydrogels were successfully prepared by EDGE in a simple mixture process. The FTIR proved that ester bonds formed as a crosslinking linkage between $\gamma$-PGA and EGDE, indicating that the hydrogel was indeed a copolymer. The morphology of $\gamma$-PGA hydrogels that swelled in equilibrium displayed a similar color as swelled ionic solutions and kept a regular cubic shape. The SEM morphology of cross-section showed the porous structure of $\gamma$-PGA hydrogels and the densely covered irregularly shaped holes, while the surface morphology showed the rough wrinkled surface of $\gamma$-PGA hydrogels without obvious holes. The ionic concentration and $\mathrm{pH}$ significantly influenced the swelling capacity of $\gamma$-PGA hydrogels whereas the temperature had no significant effects. To be specific, the swelling capacity was decreased with the increase of ionic concentration, and was increased with the increase of $\mathrm{pH}$. The swelling kinetics study indicated that $\gamma$-PGA hydrogels were ion-sensitive and presented more limited swelling kinetics in metal ion solutions with higher ionic valence numbers. And the following adsorption process demonstrated a better fitted pseudo-second-order rate equation model. Maximum swelling degree were obtained for $\gamma$-PGA hydrogels with $21.03 \mathrm{~g} \mathrm{~g}^{-1}$ in $0.154 \mathrm{~mol} \mathrm{~L}^{-1} \mathrm{NaCl}$ solution, $8.5 \mathrm{~g} \mathrm{~g}^{-1}$ in $0.154 \mathrm{~mol} \mathrm{~L}^{-1} \mathrm{CaCl}_{2}$ solution and $12.8 \mathrm{~g} \mathrm{~g}^{-1}$ in $0.154 \mathrm{~mol} \mathrm{~L}^{-1} \mathrm{FeCl}_{3}$ solution.

Overall, $\gamma$-PGA hydrogel showed ionic sensitivity and $\mathrm{pH}$ sensitivity. Characterization tests and swelling kinetics study indicated that $\gamma$-PGA hydrogel could be used in some key applications such as wound dressing, absorbent, $\mathrm{pH}$-sensitive smart material, etc.

\section{Acknowledgements}

This work was financially supported by the National Natural Science Foundation of China (No. 31200719, 51403152, 51473122), the Natural Science Foundation of Tianjin (16JCTPJC44400, 14JCQNJC14200).

\section{References}

1 J. Ahn, L. Kuffova, K. Merrett, D. Mitra, J. V. Forrester, F. Li and M. Griffith, Acta Biomater., 2013, 9, 7796-7805.

2 J. W. Freeman, M. D. Woods, D. A. Cromer, E. C. Ekwueme, T. Andric, E. A. Atiemo, C. H. Bijoux and C. T. Laurencin, J. Biomech., 2011, 44, 694-699.

3 H. Lin, C. Peng and W. Wu, J. Mater. Sci.: Mater. Med., 2014, 25, 259-269.

4 J. Peng, T. Qi, J. Liao, B. Chu, Q. Yang, W. Li, Y. Qu, F. Luo and Z. Qian, Biomaterials, 2013, 34, 8726-8740.

5 J. S. Im, J. Yun, Y. Lim, H. Kim and Y. Lee, Acta Biomater., 2010, 6, 102-109. 
6 N. Han, P. A. Bradley, J. Johnson, K. S. Parikh, A. Hissong, M. A. Calhoun, J. J. Lannutti and J. O. Winter, J. Biomater. Sci., Polym. Ed., 2013, 24, 2018-2030.

7 R. C. F. Leitao, C. P. de Moura, L. R. D. Da Silva, N. M. P. S. Ricardo, J. P. A. Feitosa, E. C. Muniz, A. R. Fajardo and F. H. A. Rodrigues, Quim. Nova, 2015, 38, 370-377.

8 Z. Mirzakhanian, K. Faghihi, A. Barati and H. R. Momeni, J. Biomater. Sci., Polym. Ed., 2015, 26, 1439-1451.

9 J. Yu, H. Zhang, Y. Li, Q. Lu, Q. Wang and W. Yang, Colloid Polym. Sci., 2016, 294, 257-270.

10 J. P. D. Garcia, M. Hsieh, B. T. Doma, D. C. Peruelo, I. Chen and H. Lee, Polymers, 2013, 6, 39-58.

11 S. C. Shukla, A. Singh, A. K. Pandey and A. Mishra, Biochem. Eng. J., 2012, 65, 70-81.

12 A. B. Scranton, B. Rangarajan and J. Klier, in ed. N. Peppas and R. Langer, Biomedical applications of polyelectrolytes, Springer, Berlin, Heidelberg, 1995, vol. 122, pp. 1-54.

13 D. Ji, T. Kuo, H. Wu, J. Yang and S. Lee, Carbohydr. Polym., 2012, 89, 1123-1130.

14 T. K. Giri, A. Thakur, A. Alexander, Ajazuddin, H. Badwaik and D. K. Tripathi, Acta Pharm. Sin. B, 2012, 2, 439-449.

15 Y. Lee, Carbohydr. Polym., 2012, 809-819.

16 R. Hua and Z. Li, Chem. Eng. J., 2014, 249, 189-200.

17 E. H. Lee, H. Uyama, O. H. Kwon and M. H. Sung, Polym. Bull., 2009, 63, 735-742.

18 S. Chung, C. Gentilini, A. Callanan, M. Hedegaard, S. Hassing and M. M. Stevens, J. Mater. Chem. B, 2013, 1, 1397-1401.

19 J. Yan, Z. Li, J. Zhang and C. Qiao, Adv. Mater. Res., 2012, 476-478, 2100-2104.

20 A. Chetouani, M. Elkolli, M. Bounekhel and D. Benachour, Polym. Bull., 2014, 71, 2303-2316.

21 I. Bajaj and R. Singhal, Bioresour. Technol., 2011, 102, 5551-5561.

22 I. Shih, P. Wu and C. Shieh, Process Biochem., 2005, 40, 28272832.

23 A. R. Bhat, V. U. Irorere, T. Bartlett, D. Hill, G. Kedia, M. R. Morris, D. Charalampopoulos and I. Radecka, $A M B$ Express, 2013, 3, 1-9.

24 A. R. Bhat, V. U. Irorere, T. Bartlett, D. Hill, G. Kedia, D. Charalampopoulos, S. Nualkaekul and I. Radecka, Int. J. Food Microbiol., 2015, 196, 24-31.

25 T. Akao, T. Kimura, Y. Hirofuji, K. Matsunaga, R. Imayoshi, J. Nagao, T. Cho, H. Matsumoto, S. Ohtono, J. Ohno, K. Taniguchi and H. Kaminishi, J. Drug Targeting, 2010, 18, 550-556.

26 F. L. Mi, Y. Y. Wu, Y. H. Lin, K. Sonaje, Y. C. Ho, C. T. Chen, J. H. Juang and H. W. Sung, Bioconjugate Chem., 2008, 19, 1248-1255.

27 Z. Rongli, L. Ling, X. Sheng, Z. Cuige, L. Xiaoya and L. Jing, Colloids Surf., A, 2015, 470, 218-223.

28 H. Poo, C. Park, M. Kwak, D. Choi, S. Hong, I. Lee, Y. T. Lim, Y. K. Choi, S. Bae, H. Uyama, C. Kim and M. Sung, Chem. Biodiversity, 2010, 7, 1555-1562.

29 X. Yu, M. Wang, Q. Wang and X. Wang, in Biosynthesis of polyglutamic acid and its application on agriculture, 2011, vol. 183-185, pp. 1219-1223.
30 C. T. Tsao, C. H. Chang, Y. Y. Lin, M. F. Wu, J. L. Wang, J. L. Han and K. H. Hsieh, Carbohydr. Res., 2010, 345, 1774-1780.

31 S. H. Choi, K. S. Whang, J. S. Park, W. Y. Choi and M. H. Yoon, Macromol. Res., 2005, 13, 339-343.

32 J. S. Im, B. C. Bai, S. J. In and Y. Lee, J. Colloid Interface Sci., 2010, 346, 216-221.

33 N. Bereli, D. Turkmen, K. Kose and A. Denizli, Mater. Sci. Eng., C, 2012, 32, 2052-2059.

34 F. Y. Siao, J. F. Lu, J. S. Wang, B. S. Inbaraj and B. H. Chen, J. Agric. Food Chem., 2009, 57, 777-784.

35 T. L. Wang, T. H. Kao, B. S. Inbaraj, Y. T. Su and B. H. Chen, J. Agric. Food Chem., 2010, 58, 12562-12567.

36 G. Yang, N. Wang and C. Zhang, Adv. Mater. Res., 2011, 183185, 125-129.

37 I. B. Bajaj and R. S. Singhal, Food Bioprocess Technol., 2011, 4, 745-752.

38 C. Zhao, Y. Zhang, X. Wei, Z. Hu, F. Zhu, L. Xu, M. Luo and H. Liu, Appl. Biochem. Biotechnol., 2013, 170, 562-572.

39 B. Mandal and S. K. Ray, Mater. Sci. Eng., C, 2014, 44, 132-143. 40 W. Zeng, W. Hu, H. Li, Y. Jing, H. Kang, Q. Jiang and C. Zhang, Chin. J. Polym. Sci., 2014, 32, 1507-1514.

41 S. Lu, Y. Ning, Z. Hao, C. Li, T. Lei, W. Yen, L. Hui and L. Ying, Mater. Sci. Eng., C, 2015, 48, 533-540.

42 J. Park, W. Choi, S. Choi and M. Yoon, J. Appl. Biol. Chem., 2005, 48, 213-217.

43 H. Jiachuan, L. Zheng, X. Wen, Y. Ning, G. Jixian, Z. Jianfei and Q. Changsheng, Mater. Sci. Eng., C, 2016, 61, 879-892.

$44 \mathrm{X}$. Yang, in Preparation and characterization of gammapoly(glutamic acid) copolymer with glycol diglycidyl ether, 2011, vol. 8, pp. 11-15.

45 F. Martello, A. Tocchio, M. Tamplenizza, I. Gerges, V. Pistis, R. Recenti, M. Bortolin, M. Del Fabbro, S. Argentiere, P. Milani and C. Lenardi, Acta Biomater., 2014, 10, 12061215.

46 M. Kunioka and H. Choi, J. Environ. Polym. Degrad., 1996, 4, 123-129.

47 J. Park, W. Choi, S. Choi and M. Yoon, J. Appl. Biol. Chem., 2005, 48, 213-217.

48 D. Huang, Z. Peng, Z. Hu, S. Zhang, J. He, L. Cao, Y. Zhou and F. Zhao, React. Funct. Polym., 2013, 73, 168-174.

49 Z. Wu, D. Huang, Z. Hu, Y. Zhou, F. Zhao, Z. Peng and B. Wang, Fibers Polym., 2014, 15, 1146-1152.

50 W. Shige, C. Xueyan, S. Mingwu, G. Rui, I. Banyai and S. Xiangyang, Colloids Surf., B, 2012, 89, 254-264.

51 M. A. Mekewi and A. S. Darwish, Mater. Res. Bull., 2015, 70, 607-620.

52 Y. Zhao, H. Su, L. Fang and T. Tan, Polymer, 2005, 46, 53685376.

53 T. Tsujimoto, J. Kimura, Y. Takeuchi, H. Uyama, C. Park and M. Sung, J. Microbiol. Biotechnol., 2010, 20, 1436-1439.

54 G. R. Mahdavinia, A. Pourjavadi, H. Hosseinzadeh and M. J. Zohuriaan, Eur. Polym. J., 2004, 40, 1399-1407.

55 N. Lee, T. Go, S. Lee, S. Jeong, G. Park, C. Hong and H. Son, Saudi J. Biol. Sci., 2014, 21, 153-158.

56 H. Omidian, S. A. Hashemi, P. G. Sammes and I. Meldrum, Polymer, 1998, 39, 6697-6704. 